\title{
REDUÇÃO DE PARADAS POR MATERIAL MOLHADO NA LAMINAÇÃO A FRIO COM A INSTALAÇÃO DE SECADOR DE FIO MÁQUINA*
}

Diogo Barcellos Moraes ${ }^{1}$

Rômulo Lourenço Vidal ${ }^{2}$ Bruno Robert de Almeida ${ }^{3}$ Fabio Conceição Ribeiro ${ }^{4}$

\section{Resumo}

O trabalho surgiu mediante a necessidade de reduzir o tempo de paradas do equipamento de laminação a frio por ruptura de fio maquina durante as reduções nos passes de laminação. Para que não ocorra ruptura do fio máquina durante as reduções nos passes, faz-se necessário uma boa lubrificação do fio maquina antes de iniciar o contato do mesmo com os anéis de laminação e para que isso ocorra de forma eficaz o fio maquina deve estar completamente seco antes de passar pela caixa de lubrificação. Sendo assim, desenvolvemos um secador de fio para que garante a secagem antes da lubrificação, de modo a evitar empedramento do sabão, má lubrificação e consequentemente rupturas.

Palavras-chave: Secagem; Secador; Laminação a frio; Lubrificante e ruptura.

\section{REDUCTION IN WET MATERIAL STOPS IN COLD ROLLING WITH THE WIRE ROD DRYER INSTALLATION}

\section{Abstract}

The work came upon the need to reduce cold rolling equipment stops by wire rod breaks in the rolling passes. In order not to break the wire rod, good lubrication is necessary before starting the contact with the rolling rings and for this to happen effectively the wire rod must be fully dried before passing through the lubrication box. Therefore, we have developed dryer device prior to lubrication, to prevent caking soap, poor lubrication and consequently breaks.

Keywords: Dryer; Cold rolling process; Break; Lubrificant.

Técnico especialista em processos, Votorantim Siderurgia, Resende, RJ, Brasil.

Engenheiro de Automação, Votorantim Siderurgia, Resende, RJ, Brasil.

Técnico de manutenção elétrica, Votorantim Siderurgia, Resende, RJ, Brasil.

Técnico de manutenção elétrica, Votorantim Siderurgia, Resende, RJ, Brasil. 


\section{INTRODUÇÃO}

No processo de laminação a frio da Votorantim Siderurgia S/A da unidade de Resende utiliza-se três passes de redução do fio máquina através de cassetes de laminação e as bitolas produzidas são $3,40 \mathrm{~mm} ; 4,20 \mathrm{~mm}$ e $5,00 \mathrm{~mm}$ nervurado. Durante o processo de redução temos atrito entre os anéis de laminação e o fio máquina que está sendo laminado. No entanto, para reduzir o calor gerado pelo atrito entre anéis de laminação e fio máquina utilizamos um lubrificante em pó para que crie uma película praticamente imperceptível ao olho humano. Essa película irá reduzir o atrito durante o processo de laminação e consequentemente rupturas do fio laminado durante o processo.

Para que a lubrificação seja eficiente, não pode ocorre empedramento do lubrificante, que acontece quando o fio máquina está molhado e passa pela caixa de lubrificação. Como não possuímos locais cobertos para armazenamento do fio máquina, ou seja, a matéria-prima a ser laminada, as bobinas ficam expostas a intempérie. Mediante a essa situação foi criado um secador de fio máquina que fica posicionado estrategicamente na entrada do equipamento, antes do decapador mecânico. Assim o material molhado, ao passar pelo secador, tem cerca de $60 \%$ da umidade retirada antes de ser decapado e logo após passa pela caixa de sabão "Lubrificante", garantindo um fio com boa lubrificação e sem causar empedramento do lubrificante em pó e consequentemente rupturas.

\section{MATERIAIS E MÉTODOS}

Com a necessidade de utilização de um sistema para secagem do arame o primeiro protótipo foi um sistema que utilizava o ar comprimido junto a um conjunto de resistências que ventilavam em um duto guia do arame na entrada do decapador mecânico. Esse protótipo apresentava algumas fragilidades como baixo grau de proteção para particulados sólidos suspensos no ar, umidade excessiva proveniente do ar comprimido entre outras.

De posse destas fragilidades, foi desenvolvido um novo sistema subdividido em 4 partes: câmara de aquecimento, ventilação de ar, monitor de temperatura e controle integrado.

A câmara de aquecimento foi desenvolvida de maneira que se evitasse a perda térmica para o ambiente, reduzindo o diâmetro de entrada e saída do arame e revestindo-a com um material refratário. O aquecimento é feito por três resistências elétricas que tem o seu funcionamento equilibrado por uma lógica de seleção de uso ou habilitando manualmente as três resistências ao mesmo tempo para que se tenha maior eficiência de secagem.

Para a injeção de ar foi instalado um ventilador centrifugo de alta rotação com o fluxo de ar direcionado para as resistências. Este sistema de ventilação foi escolhido por ser livre de umidade.

O monitoramento da temperatura da câmara de ar é feito por um transdutor de temperatura com resolução de leitura de $1^{\circ} \mathrm{C}$ e que envia os dados para sistema de controle.

O sistema de controle do secador teve como premissa, utilizar o mesmo controlador e IHM da máquina afim de se reduzir custos. Foi implementado uma lógica de controle de seleção das resistências, o controle de temperatura da câmara de ar, o controle de ventilação forçada e um sistema de proteção de falhas com alarmes do sistema. 
Toda operação é feita através de uma IHM touch onde também são exibidas informações funcionais do secador.

Utilizamos um cronograma de acompanhamento de projeto conforme figura abaixo.

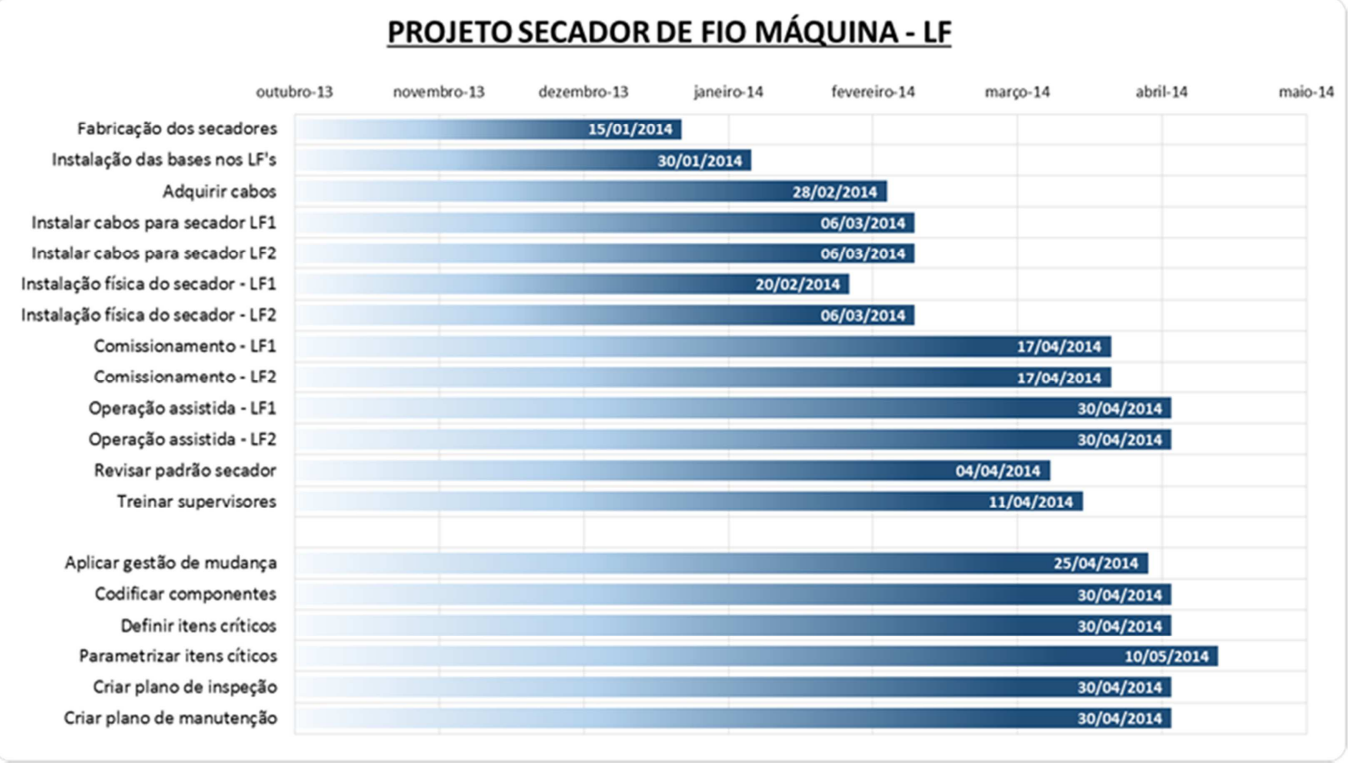

Figura 1. Cronograma do projeto.

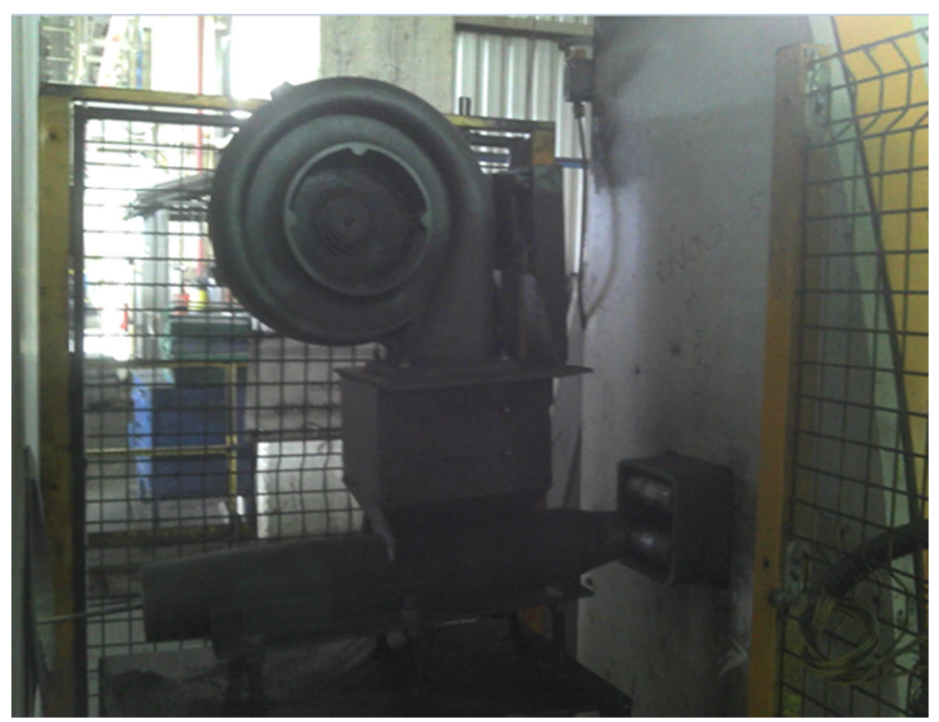

Figura 2. Foto do secador.

\subsection{Realização dos Teste}

Visando obter confiabilidade para desempenho do secador apresentado, os parâmetros de processo que foram controlados estão descritos abaixo:

- Temperatura de trabalho do secador;

- Quantidade de lubrificante;

- Velocidade de laminação;

- Quantidade de ar sobre as resistências.

\section{RESULTADOS E DISCUSSÃO}

Gráficos comparativos após a implementação do secador. 


\section{Paradas por material molhado - LF's}

ano 2013

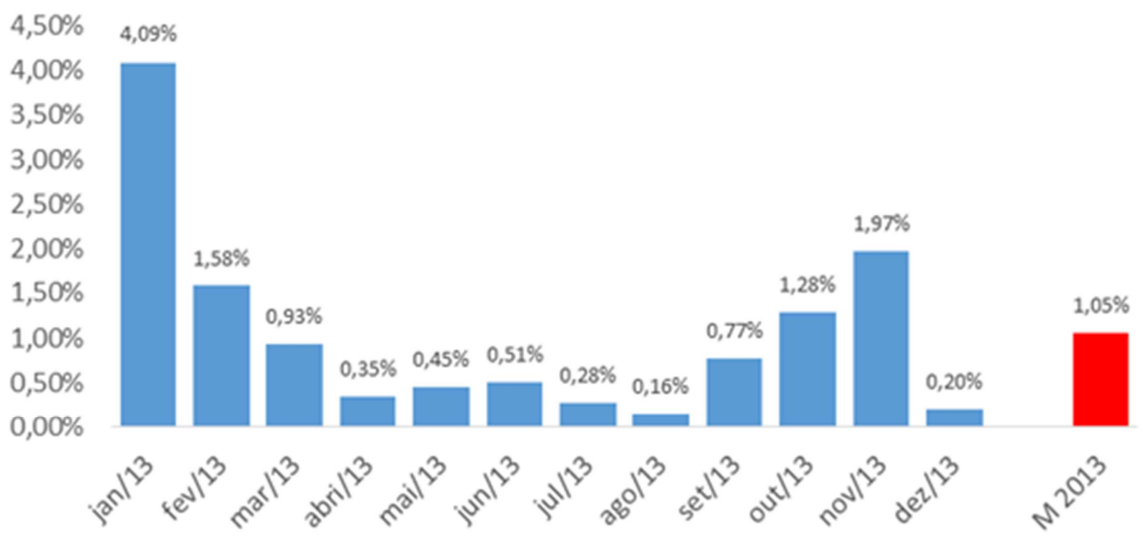

Figura 3. Gráfico de paradas por material molhado - antes do projeto.

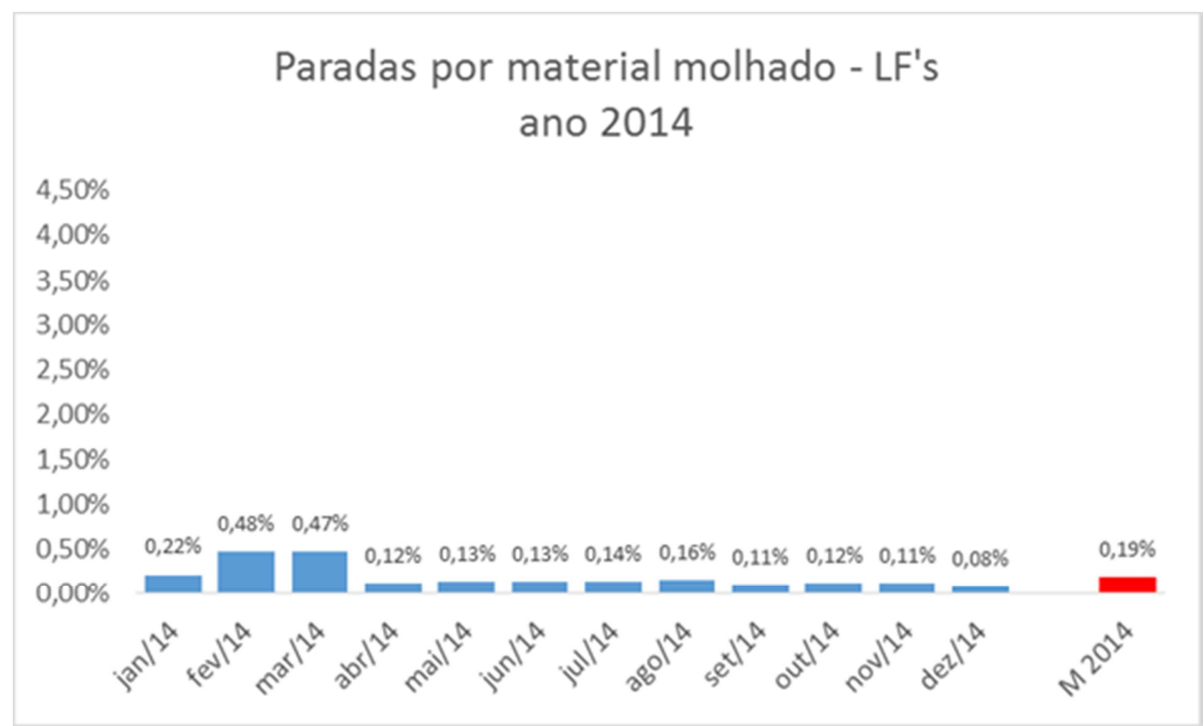

Figura 4. Gráfico de paradas por material molhado - após o projeto.

\section{CONCLUSÃO}

Após todos os testes realizado com o secador de fio máquina concluímos que o mesmo apresentou performance satisfatória durante a operação reduzindo em aproximadamente $80 \%$ as paradas por material molhado.

\section{BIBLIOGRAFIA}

1 RAUTER, O. R. Aços-Seleção - Laminação a frio - Pesquisa de Defeitos, Rio de Janeiro - GB - 1974

2 SCHMOLS+BICKENBACH - Providing Special Steel Solutions http://www.schmolzbickenbach.com.br 